\title{
Long-term efficacy and safety of human papillomavirus vaccination
}

This article was published in the following Dove Press journal:

International Journal of Women's Health

3 December 2014

Number of times this article has been viewed

\section{Rosa De Vincenzo' \\ Carmine Conte' \\ Caterina Ricci' \\ Giovanni Scambia' \\ Giovanni Capelli²}

'Division of Gynecologic Oncology, Department of Obstetrics and Gynecology, Catholic University of the Sacred Heart, Rome, ${ }^{2}$ Department of Human Sciences, Society and Health, University of Cassino and Southern Lazio, Cassino, Italy
Correspondence: Rosa De Vincenzo Division of Gynecologic Oncology, Department of Obstetrics and Gynecology, Catholic University of the Sacred Heart, 8 Largo A Gemelli, Rome 00168 , Italy

Email rosa.devincenzo@rm.unicatt.it
Abstract: In this paper, we review the published evidence about the long-term efficacy of the available human papillomavirus (HPV) vaccines and their safety profile. Two prophylactic HPV vaccines - bivalent (bHPV) and quadrivalent (qHPV) - are now available, and vaccination programs are being widely implemented, primarily targeting adolescent girls. Efficacy has been widely demonstrated for both vaccines. Since the risk of HPV exposure potentially persists throughout a woman's sexual life, vaccine duration of protection is critical to overall effectiveness. Interpreting the results of long-term efficacy studies for the two HPV vaccines can be puzzling, due to the heterogeneity of studies, different methods used in the assessment of immunogenicity, histopathological and virological end points, and statistical power issues. Moreover, an immunologic correlate of protection has not yet been established, and it is unknown whether higher antibody levels will really result in a longer duration of protection. Disease prevention remains the most important measure of long-term duration of vaccine efficacy. To date, the longest follow-up of an HPV vaccine has been 9.4 years for the bHPV vaccine. Long-term follow-up for qHPV vaccine goes up to 8 years. The vaccine continues to be immunogenic and well tolerated up to 9 years following vaccination. All randomized controlled clinical trials of the bHPV and the qHPV vaccines provide evidence of an excellent safety profile. The most common complaint reported is pain in the injection site, which is self-limiting and spontaneously resolved. The incidence of systemic adverse events (AEs), serious AEs, and discontinuations due to a serious AE reported in clinical studies are similar between the two vaccines and their control groups. In particular, no increased risk of autoimmune disease has been shown among HPV-vaccinated subjects in long-term observation studies. As these are crucial topics in HPV vaccination, it is important to establish systems for continued monitoring of vaccine immunogenicity, efficacy, and safety over time.

Keywords: HPV vaccines, effectiveness, adverse events

\section{Introduction}

Persistent infection with high-risk human papilloma virus (HPV) is a necessary step in the pathogenesis of cervical cancer. ${ }^{1}$ At least $70 \%$ of cervical cancer cases are caused by HPV 16 and HPV 18. ${ }^{2,3}$ In addition, it is recognized that HPV is the major etiological agent in squamous cell carcinoma of the anus and a significant contributor to a major proportion of squamous cell carcinoma of the vulva, vagina, penis, mouth, and oropharynx. ${ }^{4}$ A vaccine that could provide long-term protection against infection and disease caused by oncogenic HPV types would be of great value. Two prophylactic HPV vaccines are now available, and vaccination programs are being widely implemented, with young adolescent girls being the primary target group for most programs. ${ }^{5}$ However, the risk of HPV infection persists throughout a woman's sexual life. Therefore, the duration of 
protection provided by HPV vaccination is critical to overall vaccine effectiveness.

Moreover, concerns about vaccine safety and related adverse events (AEs) have been identified as an important barrier to vaccination and one of the reasons for low HPV-vaccination coverage in some settings. The aim of this review was to analyze the scientific knowledge about longterm efficacy and safety of the two available HPV vaccines: the bivalent (bHPV) and the quadrivalent (qHPV).

\section{The available vaccines: an overview}

The available prophylactic vaccines - bHPV $\left(\right.$ Cervarix $\left.{ }^{\circledR}\right)$ and qHPV $\left(\right.$ Gardasil $\left.^{\circledR}\right)$ - are noninfectious subunit vaccines composed primarily of virus-like particles (VLPs). The VLPs selfassemble from copies of $\mathrm{L} 1$, the major structural protein of the virion. ${ }^{6}$ VLPs are completely noninfectious and nononcogenic, since they do not contain the viral deoxyribonucleic acid (DNA). They form a structure that sufficiently resembles the outer shell of the authentic HPV virion so that antibodies that are induced to it react with the authentic virus. ${ }^{7}$ Although similar, bHPV and qHPV differ in several aspects, including valence, dose, production system, and adjuvants, as shown in Table 1.

\section{Phase III clinical trials and prophylactic efficacy in young women}

Phase III efficacy trials of HPV vaccines in young women were primarily designed to demonstrate efficacy in preventing

Table I Anti-HPV-vaccine types and characteristics

\begin{tabular}{|c|c|c|}
\hline & $\begin{array}{l}\text { Quadrivalent vaccine } \\
\text { (qHPV) }\end{array}$ & $\begin{array}{l}\text { Bivalent vaccine } \\
\text { (bHPV) }\end{array}$ \\
\hline \multirow{2}{*}{$\begin{array}{l}\text { Commercial name } \\
\text { and HPV types }\end{array}$} & Gardasi $^{\circledast}$ & Cervarix $^{\circledR}$ \\
\hline & HPV $6 / 11 / 16 / 18$ & HPV $16 / 18$ \\
\hline \multirow{2}{*}{$\begin{array}{l}\text { Administration } \\
\text { schedule }\end{array}$} & $9-13$ years: 0,6 months & 9-14 years: 0, 6 months \\
\hline & $\begin{array}{l}\text { Over } 13 \text { years: } 0,2 \text {, } \\
6 \text { months }\end{array}$ & $\begin{array}{l}\text { Over } 14 \text { years: } 0,1 \text {, } \\
6 \text { months }\end{array}$ \\
\hline \multirow{2}{*}{$\begin{array}{l}\text { VLP dose and } \\
\text { producer cells }\end{array}$} & LI dose $20 / 40 / 40 / 20 \mu g$ & LI dose $20 / 20 \mu g$ \\
\hline & $\begin{array}{l}\text { Saccharomyces cerevisiae } \\
\text { (baker's yeast) } \\
\text { expressing LI }\end{array}$ & $\begin{array}{l}\text { Trichoplusia ni }(\mathrm{Hi} 5) \text { insect } \\
\text { cell line infected with LI } \\
\text { recombinant baculovirus }\end{array}$ \\
\hline Adjuvant & $\begin{array}{l}225 \mu g \text { aluminum } \\
\text { hydroxyphosphate } \\
\text { sulfate (ASO4) }\end{array}$ & $\begin{array}{l}500 \mu g \text { aluminum } \\
\text { hydroxide, } 50 \mu g \\
\text { 3-O-deacylated-4- } \\
\text { monophosphoryl lipid A } \\
\text { (MPLA) }\end{array}$ \\
\hline
\end{tabular}

Notes: Gardasi ${ }^{\circledR}$ (Merck and Co., Whitehouse Station, NJ USA). Cervarix ${ }^{\circledR}$ (GlaxoSmithKline plc, London, UK).

Abbreviations: HPV, human papillomavirus; VLP, virus-like particle. incident vaccine-related HPV infection and the preneoplastic lesions caused by it. The FUTURE I ${ }^{8}$ and FUTURE II $^{9}$ trials, evaluated qHPV, and PATRICIA ${ }^{10}$ and the Costa Rica HPV Vaccine Trial ${ }^{11}$ evaluated bHPV. All of the trials were relatively large (5,500-18,500 vaccinees), blinded, randomized, and controlled and were made up of young women (mean age 20 years, range $15-26$ years). All the trials were designed to have at least 4 years of follow-up. However, interim analyses were conducted in the FUTURE I, FUTURE II, and PATRICIA trials, based on an accrual of a prespecified total number of primary end-point events. ${ }^{8-10}$ These interim analyses led to regulatory approval for both vaccines prior to completion of the trials. However, end-of-study analyses including additional end-point events have recently been published for all four studies. ${ }^{5,12,13}$

A direct comparison on efficacy of the two vaccines is hard, in terms of the heterogeneity of studies, populations (demographic factors among the countries involved in the trials), baseline prevalence of HPV infection, method of HPVantibody determination, and end points (virological or histopathological, single or composite HPV type). Differences did exist between the FUTURE I/II and PATRICIA subpopulations; to what extent these differences affected the magnitude of the differences in clinical efficacy between the HPV vaccines is not known.

Anyway, data from all these studies showed a prophylactic efficacy against vaccine type-associated end points that was uniformly high in all considered cohorts. High efficacy against vaccine HPV type-related cervical intraepithelial neoplasia (CIN) 3 was observed in the final intention-to-treat (ITT)-naïve analyses of qHPV Phase III trials. Greater than $95 \%$ efficacy and greater than $75 \%$ efficacy were also observed against vaccine type-related vulvar intraepithelial neoplasia $2 / 3$ or vaginal intraepithelial neoplasia $2 / 3$ and genital warts in the ITT-naïve and ITT cohorts, respectively. ${ }^{12}$

In the PATRICIA trial, efficacy against HPV 16/18-related CIN 3 in the total vaccinated cohort-naïve analysis was estimated at $100 \% .{ }^{13}$ As expected, efficacy was lower in the full total vaccinated cohort analysis, for which $45.7 \%$ efficacy was reported.

Although none of the Phase III studies was specifically designed to evaluate cross-type protection, both vaccines have been evaluated in many further studies for protection against infection and cervical disease associated with oncogenic types, particularly those most closely related phylogenetically to types 16 and 18 (A9 and A7 species, respectively). Cross-protection against nonvaccine types 
is an important consideration, since nonvaccine types are associated with approximately $30 \%$ of cervical cancers worldwide. ${ }^{14}$

\section{Immunogenicity of HPV vaccine}

There are several aspects of the immune response to HPV vaccines that must be taken into account in order to understand the available information and the problems to be faced in the collection of data on long-term protection. The immunogenicity of the two vaccines is expected to be different, due to the effect of the adjuvants. In fact, while qHPV vaccine uses AS04, bHPV vaccine uses aluminum hydroxide and monophosphoryl lipid A (MPL) as adjuvant (Table 1). MPL is an agonist molecule against Toll-like receptor 4 that facilitates innate immune response by stimulating Tolllike receptor 4. Both in vitro and in vivo data suggest that the addition of MPL to aluminum hydroxide enhances vaccine-induced immune response by rapidly triggering a local cytokine response, leading to the optimal activation of antigen-presenting cells. ${ }^{15}$

Moreover, all the methods used in the assessment of immunogenicity for the two vaccines are so different in most of the available studies that the comparability of the results is not always granted. Finally, no minimum protective antibody level has been determined up to now (the socalled correlate of immunity), due to the excellent efficacy and immunogenicity of the vaccine and to the absence of breakthrough lesions in immunized subjects.

In vivo, antibody titers were measured by different immunoassays throughout the three phases of the HPVvaccine trials. Proprietary reports of immune responses have used competitive Luminex immunoassay (cLIA) for the qHPV vaccine and enzyme-linked immunosorbent assay (ELISA) for the bHPV vaccine. The pseudovirion-based neutralization assay (PBNA), developed by the US National Institutes of Health, is considered the most accurate reflection of the neutralizing ability of the induced antibodies. Recently, Brown et al reported on the humoral response to the qHPV vaccine over four years as defined by total IgG and cLIA. ${ }^{16}$

In contrast to the cLIA, which evaluates the antibody response to a single unique neutralizing epitope on each of the four HPV types, ${ }^{8,9}$ the total IgG assay is a less restricted, sensitive assay that measures a broader subset of the total immune response to HPV VLP vaccination. With the cLIA assay, $90.2 \%, 95.5 \%, 98.5 \%$, and $64.8 \%$ of vaccinated women remained seropositive to HPV 6, HPV 11, HPV 16, and HPV 18, respectively, at month 48 . With the total IgG
cLIA assay, $100 \%, 100 \%, 100 \%$, and $96.7 \%$ of vaccinated women remained seropositive to HPV 6, HPV 11, HPV 16, and HPV 18, respectively, at month 48, illustrating potential important differences in serologic assays that may be used across HPV-vaccine studies. ${ }^{16}$

The immune responses induced by the two vaccines were compared in a head-to-head immunogenicity trial up to month 24 (18 months postvaccination) in women HPV DNA-negative and -seronegative prior to vaccination for the HPV types analyzed (HPV-010 [NCT00423046]). ${ }^{17,18}$ The principal geometric antibody titers (GMTs) were measured by PBNA and ELISA across all age cohorts on month 7 and on month 24 . In this study, women $(n=1,106)$ stratified by age (18-26 years, 27-35 years, 36-45 years) were randomized (1:1) to receive either bHPV vaccine or qHPV vaccine. For the entire vaccinated cohort, across all age strata, the result was that GMTs were 2.4- to 5.8-fold higher for HPV type 16 and 7.7- to 9.4-fold higher for HPV type 18 with bHPV vaccine than with qHPV vaccine $(P<0.0001)$. Similar results were obtained using ELISA.

In addition to humoral immunity, cellular immunity is responsible for viral clearance from infected cells and for the resolution of HPV-related lesions. Moreover, there is good evidence that the induction of immune memory, mediated by memory B cells, is the basis for the long-term protection afforded by HPV vaccines. ${ }^{19}$ In the Einstein et al study, at month 24 , analysis of $\mathrm{CD}^{+}{ }^{+} \mathrm{T}$-cell responses and memory B-cell responses also demonstrated that the bHPV vaccine is relatively similar to or better than the qHPV vaccine. ${ }^{18}$

Moreover, new immunological studies have demonstrated the efficacy and durability of antibody responses with respect to reduced-dosage HPV-vaccine regimens for both vaccines. ${ }^{20-22}$ In 2014, an alternative two-dose schedule (administered at 0 and 6 months) was approved in the EU for use in subjects aged 9-14 years for both vaccines (Table 1), and many jurisdictions have implemented or are contemplating the use of reduced-dosage regimens.

\section{Evaluation of long-term protection}

One of the hallmarks of vaccines that confer long-term immune protection is the development of immune memory, which is defined as vaccine-induced generation of long-lived memory immune cells that upon reexposure to the relevant antigen generate a vigorous immune response that prevents or aborts infection. ${ }^{19}$

Memory lymphocyte-mediated protection against infection may persist despite low serum antibody titers, as 
has been shown for the hepatitis B vaccine. ${ }^{23}$ For long-term protection, HPV vaccines must provide sustained production of neutralizing antibodies via generation of long-lived plasma cells, together with induction of memory B cells that can replenish the pool of antibody-secreting cells. ${ }^{19}$

In response to antigen challenge with qHPV vaccine, 54 months following completion of the primary three-dose series, subjects $(n=104)$ experienced a rapid increase in antiHPV antibody production. This suggests that the primary series of vaccinations were able to generate memory B cells. ${ }^{24}$

Results from the monovalent HPV-16 vaccine trial (Merck) showed that approximately $86 \%$ of 16 - to 23 -yearold women followed for an average of 8.5 years remained seropositive for anti-HPV 16 antibodies, and there were no breakthrough cervical disease cases. ${ }^{25}$ Moreover, evidence of immune memory 8.5 years following administration of the monovalent HPV 16 vaccine was also demonstrated. ${ }^{26}$ These results cannot be directly applied to the qHPV vaccine, but being the HPV 16 monovalent proof-of-principle vaccine used in the development program for qHPV, they may suggest that it will offer similar long-term protection, at least against HPV 16.

With regard to bHPV vaccine, women vaccinated in HPV-001 received after 7 years a fourth dose of the bHPV vaccine (024-4DV group, $n=65)$. After the fourth dose, immune responses were compared with post-first-dose immune responses in cross-vaccination controls (024-3DV group, $n=50$ ) at day 7 and month 1 . A fourth dose of bHPV vaccine triggered a rapid and strong anamnestic response in previously vaccinated women, demonstrating vaccineinduced immune memory. ${ }^{27}$

In conclusion, it seems likely that neutralizing antibody levels are the optimal surrogate marker for vaccine efficacy and vaccine-induced robust immune memory.
However, a correlate of protection has not yet been established, and the minimum level of antibody required is unknown. Disease prevention remains the most important measure of the long-term duration of vaccine efficacy.

\section{Long-term clinical efficacy in follow- up studies in naive population Quadrivalent vaccine results}

\section{Young women}

The efficacy and immunogenicity of the qHPV vaccine has been evaluated up to 5 years in an extension phase of the double-blind, randomized, placebo-controlled V501-P007 study in 241 women aged 16-23 years. ${ }^{28}$ There were no cases of HPV 6/11/16/18-related precancerous cervical dysplasia or genital warts (external genital lesions) in vaccine recipients (Table 2), and six cases in placebo recipients (efficacy 100\%, 95\% confidence interval $[\mathrm{CI}] 12 \%-100 \%$ ).

In the same study, seropositivity was maintained up to 5 years: anti-HPV 16 antibody levels remained higher in the vaccine group compared with placebo recipients. However, levels of anti-HPV 18 antibodies at 5 years were only slightly higher than those following a natural infection. It therefore appears that while the immune response of the qHPV vaccine against HPV 16 is sustained, the one against HPV 18 seems to lower progressively over time. Anyway, it has to be pointed out that these results may be due at least partially to the assay used (the cLIA), which measures only antibodies that bind to a type-specific neutralizing epitope.

The qHPV-vaccine long-term follow-up (Nordic study - Protocol 015) $)^{29}$ study is an ongoing extension of a pivotal randomized, placebo-controlled, double-blind, 4-year study ${ }^{9}$ to investigate the safety, immunogenicity, and effectiveness of qHPV in 16- to 23-year-old women. The study is taking place in four Nordic countries (Denmark, Iceland,

Table 2 Long-term studies on quadrivalent vaccine (qHPV)

\begin{tabular}{|c|c|c|c|c|}
\hline Study & Study subjects & Efficacy & Seropositivity & Follow-up \\
\hline P007 (Villa et al ${ }^{28}$ ) & $\begin{array}{l}\text { Young women } \\
\text { (age 16-23 years) }\end{array}$ & $\begin{array}{l}\text { No cases of HPV } \\
6 / 11 / 16 / 18 \text {-related } \mathrm{CIN}\end{array}$ & Maintained up to 5 years & 5 years \\
\hline $\begin{array}{l}\text { Nordic Study POI5 } \\
\left(\text { Nygard et } \mathrm{a}^{29}\right)\end{array}$ & $\begin{array}{l}\text { Young women } \\
\text { (age 16-23 years) }\end{array}$ & $\begin{array}{l}\text { No cases of HPV } \\
6 / 11 / 16 / 18 \text {-related CIN }\end{array}$ & Trend up to 9 years & 8 years \\
\hline Extension P0I8 (Iversen ${ }^{32}$ ) & $\begin{array}{l}\text { Females and males } \\
\text { (age 9-15 years) }\end{array}$ & $\begin{array}{l}\text { No cases of HPV } \\
6 / 11 / 16 / 18 \text {-related CIN }\end{array}$ & Maintained up to 8 years & 6.8 years \\
\hline Extension P0I9 (Luna et a ${ }^{35}$ ) & $\begin{array}{l}\text { Adult women } \\
\text { (age } 24-45 \text { years) }\end{array}$ & $\begin{array}{l}\text { One case of HPV } \\
6 / 11 / 16 / 18 \text {-related } \mathrm{CIN}\end{array}$ & Maintained up to 6 years & 6 years \\
\hline P020 (Giuliano et $\mathrm{al}^{36}$ ) & Males (age 16-26 years) & Three cases of EGLs & - & 3 years \\
\hline $\begin{array}{l}\text { P020 - AIN substudy } \\
\left(\text { Palefsky et } \mathrm{al}^{37}\right)\end{array}$ & $\begin{array}{l}\text { Males - MSM } \\
\text { (age 16-26 years) }\end{array}$ & $\begin{array}{l}\text { Five cases of AIN } \\
\text { due to HPV } 6 / 11 / 16 / 18\end{array}$ & - & 3 years \\
\hline
\end{tabular}

Abbreviations: HPV, human papillomavirus; CIN, cervical intraepithelial neoplasia; EGLs, external genital lesions; AIN, anal intraepithelial neoplasia; MSM, men who have sex with men. 
Norway, and Sweden), and analyzes the effectiveness and immunogenicity of the vaccine in this population of women up to 9 years after the start of vaccination (Table 2). ${ }^{29}$

Effectiveness and safety analyses started approximately 2 years following completion of Protocol 015, and are planned approximately every 2 years thereafter for 10 years. Cohort 1 comprises approximately 2,700 subjects who received qHPV vaccine at the start of Protocol 015. Cohort 2 consists of approximately 2,100 subjects who received placebo at the start of Protocol 015 and qHPV vaccine prior to entry into the Nordic study.

Vaccine effectiveness against HPV 16/18-related CIN 2 or worse was estimated by calculating the expected incidence of CIN 2/3 or worse in an unvaccinated (placebo) cohort using historical registry data. This approach, using passive cancer registry-based follow-up of HPV-vaccinated, placebovaccinated, and unvaccinated reference cohorts for long-term HPV vaccine efficacy is feasible, as was already stated in the proof-of-principle Finland study published by Rana et al. ${ }^{30}$

In the Nordic study P015 primary per-protocol analysis of effectiveness after the first 8 years, in a subset of 1,080 subjects no cases of HPV 16/18-related CIN 2 or worse were detected, nor were cases of HPV 6-, 11-, 16-, or 18-related CIN, vulvar cancer, or vaginal cancer. Seropositivity rates at 9 years for HPV 6, 11, 16, and 18 using a total IgG Luminex immunoassay were $98 \%, 96 \%, 100 \%$, and $91 \%$, respectively.

In the base study V501-P018, 1,781 sexually naïve boys and girls (aged 9-15 years) were assigned (2:1) to qHPV or saline placebo. No breakthrough cases of disease related to HPV-vaccine types were observed among vaccinated preadolescents and adolescents at 18 months postenrollment. ${ }^{31}$ In the extension study, presented at the last Eurogin conference in $2013,{ }^{32}$ the efficacy of qHPV vaccine was maintained with a median follow-up time of 6.8 years (Table 2). Depending on the HPV type, $88 \%-97 \%$ of the adolescents remained seropositive through month $96 .{ }^{32}$

\section{Adult women}

In the population of adult women (24-45 years old) qHPV effectiveness continues to be high 6 years following vaccination. The base study $\mathrm{P} 019^{33}$ in the per-protocol population reported a single case of HPV 16-related CIN 2 after 2 years of follow-up, but no disease was reported in the following analysis after 4 years. ${ }^{34}$ Moreover, the recent data analysis at 6 years (Extension P019), showed no cases of HPV 6/11/16/18-related CIN or external genital lesions during the extended follow-up phase and no evidence of HPV-type replacement in women vaccinated with qHPV. ${ }^{35}$ Seropositivity in adult women was maintained up to 6 years too (Table 2).

\section{Males}

The efficacy of qHPV vaccine in preventing infection and genital disease in males has been assessed in the randomized, double-blind, placebo-controlled V501-P020 trial in 4,065 healthy boys/men aged 16-26 years, with a follow-up of 3 years. Vaccine efficacy compared with placebo in preventing external genital lesions related to vaccine HPV types was $89.4 \%$ in the per-protocol population (Table 2). ${ }^{36}$

A substudy of the V501-P020 trial assessed the efficacy of qHPV vaccine over 36 months in preventing HPV 6-, 11-, 16-, or 18-related anal intraepithelial neoplasia in healthy males who have sex with males $(n=602)$. Efficacy of the qHPV vaccine against anal intraepithelial neoplasia associated with HPV 6, 11, 16, or 18 was $77.5 \%$ (95\% CI 39.6-93.3\%) in the per-protocol population (Table 2$).{ }^{37}$

\section{Bivalent vaccine results Young women}

Sustained high immunogenicity of the bHPV vaccine was demonstrated in adolescent girls aged 10-14 years up to 7 years after first vaccination (Table 3 ). ${ }^{38}$ The longest follow-up of an HPV vaccine to date is the one

Table 3 Long-term studies on bivalent vaccine (bHPV)

\begin{tabular}{|c|c|c|c|c|}
\hline Study & Study subjects & Efficacy & Seropositivity & Follow-up \\
\hline Extension HPV-0I3 & Females (age I0-14 years) & - & Maintained up to 7 years & 7 years \\
\hline \multicolumn{5}{|l|}{ NCT00I 96924 (Huang et $\mathrm{al}^{38}$ ) } \\
\hline $\begin{array}{l}\text { Extension HPV00 I/007/023 } \\
\text { combined (Naud et } \mathrm{al}^{42} \text { ) }\end{array}$ & $\begin{array}{l}\text { Young women } \\
\text { (age 15-25 years) }\end{array}$ & $\begin{array}{l}\text { No cases in } \\
\text { vaccine arm }\end{array}$ & Maintained up to 9.4 years & 9.4 years \\
\hline $\begin{array}{l}\text { NCT00I96937 } \\
\left(\text { Schwarz et } \mathrm{al}^{43}\right)\end{array}$ & $\begin{array}{l}\text { Young and adult women } \\
\text { (age } 15-55 \text { years) }\end{array}$ & - & Maintained up to 4 years & 4 years \\
\hline $\begin{array}{l}\text { Extension NCT00I96937 } \\
\left(\text { Schwarz et } \mathrm{al}^{44}\right)\end{array}$ & $\begin{array}{l}\text { Young and adult women } \\
\text { (age } 15-55 \text { years) }\end{array}$ & - & Maintained up to 7 years & 8 years \\
\hline $\begin{array}{l}\text { P 0II-NCT00309I66 } \\
\left(\text { Petäjä et al }{ }^{45}\right)\end{array}$ & Males (age 10-18 years) & - & Maintained up to 7 months & 7 months \\
\hline
\end{tabular}

Abbreviation: HPV, human papillomavirus. 
reached for bHPV in the HPV-001/007/023 trial. This was a double-blind, randomized, placebo-controlled study conducted in women aged 15-25 years who were HPV 16/18-seronegative, DNA-negative for 14 oncogenic HPV types, and had normal cytology before vaccination. Data have been reported in full, up to 6.4 years after first vaccination (HPV-001/007). ${ }^{39,40}$

Among women aged 15-25 years enrolled in HPV001 and who participated in the follow-up study HPV-007 (NCT00120848), a subset of 437 women from five Brazilian centers participated in this 36-month long-term follow-up (HPV-023) for a total of 113 months (9.4 years). ${ }^{41}$ During HPV-023, anti-HPV 16/18 antibodies were measured annually by ELISA and PBNA. Cervical samples were tested for HPV DNA every 6 months, and cytopathological examinations were performed annually.

Over the 9.4 years, vaccine efficacy was $95.6 \%$ (95\% CI $86.2 \%-99.1 \%$, three of 50 cases in vaccine and placebo groups, respectively) against incident infection, 100\% (84.1\%-100\%, 0 of 21$)$ against 6-month persistent infection, $100 \%(61.4 \%-100 \%, 0$ of 10$)$ against 12 -month persistent infection, $97.1 \%(82.5 \%-99.9 \%$, one of 30$)$ against $\geq$ atypical cells of undetermined significance, 95\% (68\%-99.9\%, one of 18 ) against $\geq$ low-grade squamous intraepithelial lesion, $100 \%(45.2 \%-100 \%, 0$ of 8$)$ against CIN 1+, and $100 \%(0 \%$ to $100 \%, 0$ of 3$)$ against CIN $2+$ associated with HPV $16 / 18 .^{42}$

All vaccinees remained seropositive to HPV 16/18, with antibody titers remaining severalfold above natural infection levels up to 9.4 years postvaccination (Table 3 ). Due to the low number of events, this extension study (HPV-023) lacked sufficient statistical power to show efficacy against more stringent outcomes (persistent infection, cytology, and histology including CIN 2+).

\section{Adult women}

Other studies of the bHPV vaccine have evaluated long-term immunogenicity in older women (and in adolescent girls, the primary target population for vaccination programs). In women aged $15-55$ years, $>99 \%$ of women remained seropositive for anti-HPV 16 and anti-HPV 18 antibodies up to 4 years after vaccination (Table 3$).{ }^{43}$ In the older agegroup of this study, there was a strong correlation between antibody levels in serum and cervicovaginal secretions, suggesting sustained transudation of serum antibodies to the cervical epithelium. In the extension study presented at the last Eurogin in 2013, seropositivity was maintained up to 7 years (Table 3 ). ${ }^{44}$

\section{Males}

Healthy males aged 10-18 years were randomized (2:1 ratio) to receive bHPV vaccine $(n=181)$ or hepatitis B virus control vaccine $(n=89)$ at 0,1 , and 6 months, and were followed for 7 months in study P011-NCT00309166 (Table 3). ${ }^{45}$ The bHPV vaccine elicited substantially higher antibody levels for both antigens in boys aged 10-18 years or 10-14 years, when compared with women aged 15-25 years or girls aged 10-14 years, respectively, from a previous study. ${ }^{46}$ Postvaccination antibody levels for both HPV 16 and 18 were observed to be up to threefold higher in boys than in women. A comparative analysis of bHPV and qHPV vaccine-study efficacy against CIN 2+ disease through follow-up years in young women is presented in Figure 1, in order to summarize the timetable of the available studies.

\section{Long-term safety}

The safety and tolerability of both vaccines have been evaluated in many studies, with similar profiles in the vaccinated and control groups, irrespective of age or ethnicity. Safety studies indicated that local and systemic injection-related symptoms were generally mild. Serious AEs that were considered vaccine-related were rare and very similar to other compulsory, well-known vaccine types. ${ }^{47}$ The most common AE reported for both vaccines in trials and clinical experience is injectionsite reaction, particularly described as pain, swelling, and erythema in $95 \%$ of cases of light-moderate intensity. ${ }^{48}$ This figure has been confirmed by the recent work of Gonçalves et al on both vaccines in postmarketing experience. ${ }^{49}$ Systemic symptoms, such as fever, nausea, vomiting, dizziness, myalgia, and diarrhea, were reported. Severe AEs, such as persistent headache, hypertension, gastroenteritis, and bronchospasm, were described in no more than $0.5 \%{ }^{49}$

Compliance rates with the three-dose schedule were high in the registrative trials for both vaccines $(>84 \%)$. Pregnancy outcomes received special attention given the target age. No statistically significant increase in miscarriage rates has been reported for either of the vaccines. ${ }^{50}$ From registered trials, both HPV vaccines have been classified as Pregnancy Category B by the US Food and Drug Administration. Therefore, the vaccine is not recommended for pregnant women, because there are not enough data to ensure safety to the fetus. ${ }^{51,52}$ Anyway, the pregnant women that were recorded and observed in the registrative trials had the same rate of congenital abnormalities, consistent with those seen in young women. ${ }^{53-55}$ Studies have also demonstrated efficacy and safety of the vaccines in heterosexual and homosexual men. ${ }^{56}$ 


\begin{tabular}{|c|c|c|c|c|c|c|}
\hline qHPV & \multicolumn{2}{|c|}{$\begin{array}{c}\text { FUTURE I and II } \\
\text { (Garland et al }{ }^{8}, \text { FUTURE II } \\
\text { Study Group }{ }^{9} \text { ) }\end{array}$} & \multicolumn{2}{|c|}{$\begin{array}{l}\text { HPV-P } 007 \\
\left(\text { Villa et } \mathrm{al}^{28}\right)\end{array}$} & \multicolumn{2}{|c|}{$\begin{array}{l}\text { Nordic study P015 } \\
\left.\text { (Nygård et } \mathrm{al}^{29}\right)\end{array}$} \\
\hline Young women & \multicolumn{2}{|c|}{ 16-26 years } & \multicolumn{2}{|c|}{ 16-23 years } & & 16-23 years \\
\hline $\begin{array}{l}\text { Efficacy against } \\
\text { HPV-6/11/16/18 } \\
\text { CIN2 + related }\end{array}$ & \multicolumn{2}{|c|}{$\begin{array}{c}100 \% \\
(95 \% \mathrm{Cl}: 94-100)\end{array}$} & \multicolumn{2}{|c|}{$\begin{array}{c}100 \% \\
(95 \% \text { Cl: } 12-100)\end{array}$} & \multicolumn{2}{|r|}{$\begin{array}{c}100 \% \\
(\mathrm{NA})\end{array}$} \\
\hline$y_{0 M} \not x$ & & & \multicolumn{2}{|l|}{ 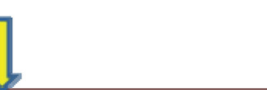 } & \multicolumn{2}{|c|}{ 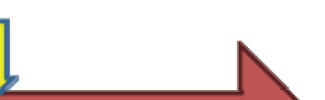 } \\
\hline FU (years) & \multicolumn{2}{|l|}{3.6} & $\begin{array}{ll}5 & 6.4\end{array}$ & & \multicolumn{2}{|c|}{8.4} \\
\hline \multicolumn{7}{|l|}{$\sum_{x}^{0 M} \sum_{x}^{1 M}$} \\
\hline bHPV & $\begin{array}{c}\text { HPV } 001 \\
\left(\text { Harper et } \mathrm{al}^{39}\right)\end{array}$ & (Rc & $\begin{array}{l}007 \\
\text { nowski } \\
\left.a^{40}\right)\end{array}$ & $\begin{array}{r}\text { HP } \\
\text { (Rotel } \\
\text { et }\end{array}$ & & $\begin{array}{c}\text { Extension } \\
\text { HPV } 023 \\
\left(\text { Naud et } \mathrm{al}^{42}\right)\end{array}$ \\
\hline Young women & $15-25$ years & & 25 years & 15 & & $15-25$ years \\
\hline $\begin{array}{l}\text { Efficacy against } \\
\text { HPV-16/18 } \\
\text { CIN } 2 \pm \text { related }\end{array}$ & $\begin{array}{c}\text { NA } \\
\text { Cytological } \\
\text { abnormalities } 93.5 \% \\
(95 \% \text { Cl: } 51.3-99.1)\end{array}$ & $(95 \%$ & $\begin{array}{l}0 \% \\
51.3-100)\end{array}$ & $\begin{array}{r}10 \\
(95 \% \mathrm{C}\end{array}$ & & $\begin{array}{c}100 \% \\
(95 \% \mathrm{Cl}: 0-100)\end{array}$ \\
\hline
\end{tabular}

Figure I Long-term clinical efficacy in follow-up studies in naïve populations.

Abbreviations: HPV, human papillomavirus; qHPV, quadrivalent vaccine; bHPV, bivalent vaccine; $\mathrm{Cl}$, confidence interval; $\mathrm{CIN}$, cervical intraepithelial neoplasia; $\mathrm{NA}$, not applicable; FU, follow-up; M, months.

The safety profiles of HPV vaccines have been confirmed - out of clinical trials - by clinical practice and their use worldwide, and they have been included in the immunization schedules of 28 countries. There has not been any absolute contraindication so far for the use of these vaccines. $^{49}$

Although it has been demonstrated that safety is not a major issue concerning HPV vaccines, in real life, together with costs, it still represents a limiting factor for their use in many countries. Parental opinions and attitudes probably play a key role in the success of new vaccines. Following the Centers for Disease Control and Prevention's NIS Teen 2012 study ${ }^{57}$ the top five reasons for not vaccinating daughters among parents with no intention to vaccinate in the next 12 months were: not needed or necessary $(19.1 \%)$, not recommended by provider (14.2\%), safety concern/side effects (13.3\%), lack of knowledge (12.6\%), and not sexually active $(10.1 \%)$.

In particular, concerns about systemic symptoms (such as fever, nausea, vomiting, gastritis, dizziness, myalgia, and diarrhea), serious AEs (such as syncope, allergic reaction/ anaphylaxis, persistent headache, hypertension, gastroenteritis, bronchospasm, and venous thromboembolism), autoimmune disease (AD) (such as hypothyroidism, rheumatoid arthritis, Behçet's syndrome, Raynaud's disease, type 1 diabetes, and vitiligo), and neurological disorders (such as epilepsy, paralysis, Guillain-Barré syndrome, central demyelination, and multiple sclerosis) are the real worries, catching much more attention than the very common injection-site reaction.

There is a wide range of immunomediated disease with different etiologies that may be triggered by genetic or infective conditions. Vaccination stimulates the immune system to produce antigen-specific immunity. Because AD etiologies also involve stimulation of the immune system, it has been suggested that vaccination may trigger ADs. The mechanism most frequently proposed is molecular mimicry, in which antigens of the host are recognized as being similar to antigens of the vaccine, thus provoking the development of autoantibodies. Moreover, potentiation or activation of previously unrecognized ADs in susceptible individuals is a theoretical concern related to the immunostimulatory effects of new adjuvants. ${ }^{58}$

ADs are not rare in the adolescent and young adult population, especially in women. Therefore, the large-scale 
implementation of any immunization in adolescents and young adults is inevitably followed by cases of ADs occurring in temporal association with immunizations. It is a significant challenge to distinguish causal from temporal associations.

With regard to the previous consideration, a comparative analysis of data on HPV vaccines' serious ADs is complex. A list of principal studies on serious AEs in the long-term safety evaluation of HPV vaccines is reported and detailed in Table 4. ${ }^{42,55,58-64}$ A registry-based cohort study of 997,585 girls aged 10-17 years conducted in Sweden and Denmark compared AEs in 296,826 girls receiving qHPV vaccine with the incidence of the conditions in unvaccinated girls, and did not find evidence supporting an association between the vaccine and autoimmune, neurological, or venous thromboembolism AEs. ${ }^{63}$ Other surveillance studies have likewise not found an increased risk of autoimmune disorders associated with qHPV vaccine. ${ }^{61,64}$
Recently, a pooled analysis of large-scale and long-term safety data from the 42 completed/ongoing clinical trials with bHPV vaccine has been published. Overall, 31,173 adolescent girls/women received bHPV vaccine alone (HPV group), 2,166 received bHPV vaccine coadministered with another vaccine, and 24,241 were controls, with a mean follow-up of 39 months. The incidence of unsolicited AEs reported within 30 days after any dose was similar between the HPV and control groups (30.8\% and 29.7\%, respectively). During the entire study period, reports of medically significant conditions (25.0\% and $28.3 \%$, respectively) and serious AEs (7.9\% and $9.3 \%$, respectively) were also similarly distributed between groups. Potential immune-mediated diseases within 1 year were reported by $0.2 \%$ of bHPV vaccines and controls. ${ }^{58}$

The overall incidence rates of spontaneous abortion (15.1\% in bHPV recipients and $11.1 \%$ in control recipients in controlled studies), although showing a tendency to occur more frequently versus control vaccine around the

Table 4 HPV vaccines: serious AEs in long-term safety evaluation

\begin{tabular}{|c|c|c|c|}
\hline $\begin{array}{l}\text { Study (vaccine } \\
\text { type) }\end{array}$ & Assessment (sample) & End points & Results \\
\hline Slade et $\mathrm{al}^{55}$ (qHPV) & $\begin{array}{l}\text { Postmarketing US passive } \\
\text { surveillance reports (VAERS) } \\
\text { (12,424 AE reports/23 million doses) }\end{array}$ & $\begin{array}{l}\text { Syncope, dizziness, nausea, headache, local } \\
\text { injection-site reactions, hypersensitivity } \\
\text { reactions including anaphylaxis, Guillain-Barré } \\
\text { syndrome (GBS), transverse myelitis, } \\
\text { pancreatitis, venous thromboembolic events } \\
\text { (VTEs), deaths, and pregnancy outcomes }\end{array}$ & $\begin{array}{l}\text { Most } A E \text { rates not greater than } \\
\text { background rates } \\
\text { Syncope was reported with } \\
\text { higher frequency, but only in } 5 \% \\
\text { lead to a serious } A E\end{array}$ \\
\hline $\begin{array}{l}\text { Descamps et } \mathrm{al}^{59} \\
\text { (bHPV) }\end{array}$ & $\begin{array}{l}\text { Pooled analysis of eleven clinical } \\
\text { trials ( } 16, \mid 42 \text { subjects/45,988 doses) }\end{array}$ & $\begin{array}{l}\text { Serious AEs and medically significant } \\
\text { conditions }\end{array}$ & $\begin{array}{l}\text { No difference from placebo } \\
\text { group }\end{array}$ \\
\hline Gee et $\mathrm{al}^{60}$ (qHPV) & $\begin{array}{l}\text { Longitudinal cohort in seven MCOs } \\
(600,558 \text { doses })\end{array}$ & $\begin{array}{l}\text { GBS, stroke, VTE, appendicitis, anaphylaxis, } \\
\text { seizure, syncope, or allergic reaction }\end{array}$ & $\begin{array}{l}\text { No statistically significant } \\
\text { increased risk }\end{array}$ \\
\hline Chao et $\mathrm{al}^{61}$ (qHPV) & $\begin{array}{l}\text { Longitudinal cohort in two MCOs } \\
\text { (189,629 subjects) }\end{array}$ & Autoimmune conditions & No autoimmune safety signals \\
\hline Klein et $\mathrm{al}^{62}(\mathrm{qHPV})$ & $\begin{array}{l}\text { Longitudinal cohort in two MCOs } \\
\text { (189,629 subjects/346,972 doses), } \\
\text { same cohort as Chao et } \mathrm{al}^{61}\end{array}$ & $\begin{array}{l}\text { Emergency department admission } \\
\text { and hospitalization }\end{array}$ & $\begin{array}{l}\text { Association with syncope and } \\
\text { skin infection, but not with } \\
\text { autoimmune diseases and VTEs }\end{array}$ \\
\hline $\begin{array}{l}\text { Arnheim-Dahlström } \\
\text { et } \mathrm{al}^{63} \text { (qHPV) }\end{array}$ & $\begin{array}{l}\text { Register-based cohort study } \\
(296,826 \text { subjects/696,420 doses) }\end{array}$ & $\begin{array}{l}\text { Behçet's syndrome, Raynaud's } \\
\text { disease, and type I diabetes; VTEs }\end{array}$ & $\begin{array}{l}\text { No-temporal relationship with } \\
\text { Behçet's, Raynaud's, or type I } \\
\text { diabetes; no association with VTEs }\end{array}$ \\
\hline $\begin{array}{l}\text { Grimaldi-Bensouda } \\
\text { et } \mathrm{al}^{64}(\mathrm{qHPV})\end{array}$ & $\begin{array}{l}\text { Case-control study ( } 2 \text { I I cases } \\
\text { and } 875 \text { matched controls) }\end{array}$ & $\begin{array}{l}\text { Six types of autoimmune disorders (ADs): } \\
\text { idiopathic thrombocytopenic purpura, } \\
\text { connective tissue disorders, central } \\
\text { demyelination and multiple sclerosis (MS), } \\
\text { GBS, type I diabetes, and thyroid disorders }\end{array}$ & $\begin{array}{l}\text { No evidence of an increase in the } \\
\text { risk of the studied ADs, except } \\
\text { for a lower OR for central } \\
\text { demyelination/MS }\end{array}$ \\
\hline $\begin{array}{l}\text { Angelo et } \mathrm{al}^{58} \\
\text { (bHPV) }\end{array}$ & $\begin{array}{l}\text { Pooled analysis of AEs in } 42 \text { clinical } \\
\text { trials ( } 31,173 \text { subjects/96,704 doses) }\end{array}$ & Spontaneous abortion, appendicitis & $\begin{array}{l}\text { No differences of incidence } \\
\text { and distribution with placebo } \\
\text { group. No increased risk of any } \\
\text { immunologic disease }\end{array}$ \\
\hline Naud et $\mathrm{al}^{42}$ (bHPV) & $\begin{array}{l}\text { Clinical trial safety extension } \\
\text { study ( } 224 \text { subjects) }\end{array}$ & $\begin{array}{l}\text { Adverse events, chronic and autoimmune } \\
\text { diseases: five cases each for gastritis, spontaneous } \\
\text { abortion, depression, and hypertension; } \\
\text { two cases of hypothyroidism; one case each } \\
\text { for rheumatoid arthritis and vitiligo }\end{array}$ & No difference with placebo group \\
\hline
\end{tabular}

Abbreviations: HPV, human papillomavirus; qHPV, quadrivalent vaccine; AE, adverse event; VAERS, Vaccine Adverse Event Reporting System; MCOs, managed care organizations; OR, odds ratio; bHPV, bivalent vaccine. 
administration of the first and second doses, are within the published range in the general population in the UK and the US (up to $15 \%$ across all ages). ${ }^{58}$

The Global Advisory Committee on Vaccine Safety (GACVS) was established by the World Health Organization (WHO) to provide independent, scientifically rigorous advice on vaccine-safety issues of potential global importance. The GACVS held its 29th meeting in Geneva, Switzerland in December 2013. ${ }^{65}$ The committee reviewed different topics and considered all available evidence on the safety of HPV vaccines, and concluded that both commercially available vaccines are safe. The most common complaint reported was pain at the injection site, which was largely self-limiting and resolved spontaneously.

The incidence of chronic pain resembling complex regional pain syndrome reported in Japan (24 cases reported to date) is being investigated, but so far the expert advisory committee has not been able to ascertain a causal relationship with vaccination. ${ }^{66,67}$

Having reviewed all available data, the International Federation of Gynecology and Obstetrics (FIGO) Gynecologic Oncologic Committee and Subcommittee for Cervical Cancer Prevention support the continued administration of the HPV vaccines in appropriate populations. ${ }^{68}$

\section{Conclusion}

HPV-vaccination programs have been implemented in many countries, and decisions on vaccination strategies had to be taken before reaching a definitive evidence of long-lasting protection. It is important to establish systems for continued monitoring of vaccine immunogenicity and efficacy over time, and the manufacturers of both HPV vaccines are committed to long-term follow-up.

If prophylactic HPV vaccines confer long-lasting immunity, they could potentially prevent a large number of cases of cervical cancer globally. Long-term immunity conferred by these vaccines is particularly important, because the cost and programmatic implications of administration of a booster dose to young women could be overwhelming in the developing world, where the HPV vaccines are most needed. Population-based follow-up studies should provide valuable information on the long-term effect of prophylactic HPV vaccines.

In the meantime, head-to-head studies of the two vaccines have provided evidence that the bHPV vaccine induces a stronger immune response than the qHPV vaccine, with higher levels of neutralizing antibodies maintained at 2 years postvaccination. ${ }^{17,18} \mathrm{~A}$ recent study of the bHPV vaccine showed that levels of neutralizing antibodies against both HPV 16 and HPV 18 remain severalfold above natural infection levels up to 9.4 years after vaccination. ${ }^{42}$ In contrast, where the immune response against HPV 16 is maintained with the qHPV vaccine up to 5 years, the response against HPV 18 seems to lower in time when measured by the cLIA. ${ }^{14}$ In this regard, it is interesting to note that efficacy of the qHPV vaccine against clinical end points associated with HPV 18 is maintained at 5 years, despite waning antibody levels. ${ }^{69}$ Recent data, presented at the last Eurogin conference, showed efficacy of qHPV vaccine maintained up to 8 years and a trend of seropositivity up to 9 years. These data have been reported in the new summaries of product characteristics of the products. ${ }^{70}$

However, no immune correlate of protection has been established for HPV vaccines, and it is unknown whether higher antibody levels will really result in a longer duration of protection. Both vaccines were shown to raise a valid immune memory, a hallmark of long-term protection, as evidenced by the rapid and robust increase in vaccine type-specific antibodies in response to challenge. As crossprotection may make a valuable contribution to overall vaccine efficacy, it is important to understand its value and its likely duration as well.

The potential benefits deriving from expanding HPVtype coverage with the forthcoming Merck nonavalent HPV vaccine - whose Phase III trials are about to be completed have to be considered as an interesting future perspective that might change the scenario in HPV vaccination. ${ }^{71}$

The safety and tolerability of both vaccines have been evaluated in many studies. The most common $\mathrm{AE}$ reported for both vaccines in trials and clinical experience is injection-site reaction, particularly described as pain, swelling, and erythema. Both the vaccines are well tolerated, and the number of systemic AEs, serious AEs, and discontinuations due to a serious event reported in clinical studies are similar between the two vaccines and control groups.

The WHO GACVS reviewed the safety of HPV vaccination in December 2013. ${ }^{65}$ The committee considered all available evidence on HPV vaccination, and concluded that both commercially available vaccines are safe. Having reviewed all available data, the FIGO Gynecologic Oncologic Committee and Subcommittee for Cervical Cancer Prevention support the continued administration of the HPV vaccines in appropriate populations. ${ }^{68}$

In addition, the predicted duration of anti-HPV 16 and -HPV 18 antibody responses following vaccination were explored by mathematical modeling. Factors that can 
influence long-term immunity include the peak level of antibody response 1 month after the last vaccine dose, rates of B-cell decay and proliferation, B-cell immunologic memory, cell-mediated immunity, and individual variability. ${ }^{72}$ Based on data from the initial and follow-up studies, the results of the modeling predict that anti-HPV 16 and anti-HPV 18 antibody levels will decrease, but will remain severalfold higher than those associated with natural infection for at least 20 years postvaccination. These results provide circumstantial evidence that should a booster be needed, this need will not occur before a substantial amount of time has elapsed after vaccination, which is consistent with previous modeling results. ${ }^{42}$

While the clinical relevance of long-term antibody persistence is being investigated, modeling of predicted GMTs may be informative for clinicians and policy makers until these long-term observational data are available. ${ }^{72}$ The WHO has established a global HPV laboratory network with a main goal: the harmonization of HPV laboratory procedures in support of consistent monitoring and reporting of HPV studies in the future. ${ }^{73,74}$

\section{Disclosure}

The authors report no conflicts of interest in this work.

\section{References}

1. Walboomers JM, Jacobs MV, Manos MM, et al. Human papillomavirus is a necessary cause of invasive cervical cancer worldwide. J Pathol. 1999;189(1):12-19.

2. de Sanjose S, Quint WG, Alemany L, et al. Human papillomavirus genotype attribution in invasive cervical cancer: a retrospective crosssectional worldwide study. Lancet Oncol. 2010;11(11):1048-1056.

3. Bosch FX, Burchell AN, Schiffman M, et al. Epidemiology and natural history of human papillomavirus infections and type-specific implications in cervical neoplasia. Vaccine 2008;26 Suppl 10:K1-K16.

4. Parkin DM, Bray F. Chapter 2: The burden of HPV-related cancers. Vaccine. 2006;24 Suppl 3:S3/11-25.

5. Schiller JT, Castellsagué X, Garland SM. A review of clinical trials of human papillomavirus prophylactic vaccines. Vaccine. 2012; 30 Suppl 5:F123-F138.

6. Kirnbauer R, Booy F, Cheng N, Lowy DR, Schiller JT. Papillomavirus L1 major capsid protein self-assembles into viruslike particles that are highly immunogenic. Proc Natl Acad Sci USA. 1992;89(24):12180-12184.

7. Stanley M. HPV - immune response to infection and vaccination. Infect Agent Cancer. 2010;5:19.

8. Garland SM, Hernandez-Avila M, Wheeler CM, et al. Quadrivalent vaccine against human papillomavirus to prevent anogenital diseases. N Engl J Med. 2007;356(19):1928-1943.

9. FUTURE II Study Group. Quadrivalent vaccine against human papillomavirus to prevent high-grade cervical lesions. $N$ Engl J Med. 2007;356(19):1915-1927.

10. Paavonen J, Jenkins D, Bosch FX, et al. Efficacy of a prophylactic adjuvanted bivalent $\mathrm{L} 1$ virus-like-particle vaccine against infection with human papillomavirus types 16 and 18 in young women: an interim analysis of a phase III double-blind, randomised controlled trial. Lancet. 2007;369(9580):2161-2170.
11. Herrero R, Hildesheim A, Rodríguez AC, et al. Rationale and design of a community-based double-blind randomized clinical trial of an HPV 16 and 18 vaccine in Guanacaste, Costa Rica. Vaccine. 2008;26(37):4795-4808.

12. Muñoz N, Kjaer SK, Sigurdsson K, et al. Impact of human papillomavirus (HPV)-6/11/16/18 vaccine on all HPV-associated genital diseases in young women. J Natl Cancer Inst. 2010;102(5):325-339.

13. Lehtinen M, Paavonen J, Wheeler CM, et al. Overall efficacy of HPV-16/ 18 AS04-adjuvanted vaccine against grade 3 or greater cervical intraepithelial neoplasia: 4-year end-of-study analysis of the randomised, double-blind PATRICIA trial. Lancet Oncol. 2012;13(1):89-99.

14. De Vincenzo R, Ricci C, Conte C, Scambia G. HPV vaccine crossprotection: highlights on additional clinical benefit. Gynecol Oncol. 2013;130(3):642-651. Review.

15. Iwasaki A, Medzhitov R. Toll-like receptor control of the adaptive immune responses. Nat Immunol. 2004;5(10):987-995.

16. Brown DR, Garland SM, Ferris DG, et al. The humoral response to Gardasil over four years as defined by total $\mathrm{IgG}$ and competitive Luminex immunoassay. Hum Vaccin. 2011;7(2):230-238.

17. Einstein MH, Baron M, Levin MJ, et al. Comparison of the immunogenicity and safety of Cervarix and Gardasil human papillomavirus (HPV) cervical cancer vaccines in healthy women aged 18-45 years. Hum Vaccin. 2009;5(10):705-719.

18. Einstein MH, Baron M, Levin MJ, et al. Comparative immunogenicity and safety of human papillomavirus (HPV)-16/18 vaccine and HPV-6/11/16/18 vaccine: follow-up from months $12-24$ in a Phase III randomized study of healthy women aged 18-45 years. Hum Vaccin. 2011;7(12):1343-1358.

19. Stanley M. Potential mechanisms for HPV vaccine-induced long-term protection. Gynec Oncol. 2010;118(Suppl 1):S2-S7.

20. Kreimer AR, Rodriguez AC, Hildesheim A, et al. Proof-of-principle evaluation of the efficacy of fewer than three doses of a bivalent HPV16/18 vaccine. J Natl Cancer Inst. 2011;103(19):1444-1451.

21. Dobson SR, McNeil S, Dionne M, et al. Immunogenicity of 2 doses of HPV vaccine in younger adolescents vs 3 doses in young women: a randomized clinical trial. JAMA. 2013;309(17):1793-1802.

22. Krajden M, Cook D, Yu A, et al. Assessment of HPV 16 and HPV 18 antibody responses by pseudovirus neutralization, Merck cLIA and Merck total IgG LIA immunoassays in a reduced dosage quadrivalent HPV vaccine trial. Vaccine. 2014;32(5):624-630.

23. Ward SM, Phalora P, Bradshaw D, Leyendeckers H, Klenerman P. Direct ex vivo evaluation of long-lived protective antiviral memory B cell responses against hepatitis B virus. J Infect Dis. 2008;198(6): 813-817.

24. Olsson SE, Villa LL, Costa RL, et al. Induction of immune memory following administration of a prophylactic quadrivalent human papillomavirus (HPV) types 6/11/16/18 L1 virus-like particle (VLP) vaccine. Vaccine. 2007;25(26):4931-4939.

25. Rowhani-Rahbar A, Mao C, Hughes JP, et al. Longer term efficacy of a prophylactic monovalent human papillomavirus type 16 vaccine. Vaccine. 2009;27(41):5612-5619.

26. Rowhani-Rahbar A, Alvarez FB, Bryan JT, et al. Evidence of immune memory 8.5 years following administration of a prophylactic human papillomavirus type 16 vaccine. J Clin Virol. 2012;53(3):239-243.

27. Moscicki AB, Wheeler CM, Romanowski B, et al. Immune responses elicited by a fourth dose of the HPV-16/18 AS04-adjuvanted vaccine in previously vaccinated adult women. Vaccine. 2012;31(1):234-241.

28. Villa LL, Ault KA, Giuliano AR, et al. Immunologic responses following administration of a vaccine targeting human papillomavirus types 6 , 11, 16, and 18. Vaccine. 2006;24(27-28):5571-5583.

29. Nygård M, Krüger Kjaer S, Dillner J, et al. Long-term effectiveness and immunogenicity of Gardasil ${ }^{\mathrm{TM}}$ in the Nordic countries. Poster presented at: Eurogin 2013: HPV at a Crossroads - 30 Years of Research and Practice; November 3-6, 2013; Florence, Italy.

30. Rana MM, Huhtala H, Apter D, et al. Understanding long-term protection of human papillomavirus vaccination against cervical carcinoma: cancer registry-based follow-up. Int J Cancer. 2013;132(12):2833-2838. 
31. Reisinger KS, Block SL, Lazcano-Ponce E, et al. Safety and persistent immunogenicity of a quadrivalent human papillomavirus types $6,11,16,18 \mathrm{~L} 1$ virus-like particle vaccine in preadolescents and adolescents: a randomized controlled trial. Pediatr Infect Dis J. 2007;26(3):201-209.

32. Iversen OE. Long-term extension study of Gardasil in adolescents: results through month 96. Poster presented at: Eurogin 2013: HPV at a Crossroads - 30 Years of Research and Practice; November 3-6, 2013; Florence, Italy.

33. Muñoz N, Manalastas R Jr, Pitisuttithum P, et al. Safety, immunogenicity, and efficacy of quadrivalent human papillomavirus (types 6, 11, 16, 18) recombinant vaccine in women aged $24-45$ years: a randomised, doubleblind trial. Lancet. 2009;373(9679):1949-1957.

34. Castellsagué X, Muñoz N, Pitisuttithum P, et al. End-of-study safety, immunogenicity, and efficacy of quadrivalent HPV (types 6, 11, 16, 18) recombinant vaccine in adult women 24-45 years of age. Br J Cancer. 2011;105(1):28-37.

35. Luna J, Plata M, Gonzalez M, et al. Long-term follow-up observation of the safety, immunogenicity, and effectiveness of Gardasil ${ }^{\mathrm{TM}}$ in adult women. PLoS One. 2013;8(12):e83431.

36. Giuliano AR, Palefsky JM, Goldstone S, et al. Efficacy of quadrivalent HPV vaccine against HPV infection and disease in males. $N$ Engl J Med. 2011;364(5):401-411.

37. Palefsky JM, Giuliano AR, Goldstone S, et al. HPV vaccine against anal HPV infection and anal intraepithelial neoplasia. $N$ Engl J Med. 2011;365(17):1576-1585.

38. Huang LM, Schwarz TF, Valencia A, et al. Long-term immunogenicity and safety of the HPV-16/18 as04-adjuvanted vaccine in adolescent girls aged 10-14 years: 7-year follow-up. Poster presented at: Eurogin 2013: HPV at a Crossroads - 30 Years of Research and Practice; November 3-6, 2013; Florence, Italy.

39. Harper DM, Franco ELS, Wheeler C, et al. Efficacy of a bivalent L1 virus-like particle vaccine in prevention of infection with human papillomavirus types 16 and 18 in young women: a randomised controlled trial. Lancet. 2004;364(9447):1757-1765.

40. GlaxoSmithKline Vaccine HPV-007 Study Group, Romanowski B, de Borba PC, et al. Sustained efficacy and immunogenicity of the human papillomavirus (HPV)-16/18 AS04-adjuvanted vaccine: analysis of a randomised placebo-controlled trial up to 6.4 years. Lancet. 2009;374(9706):1975-1985.

41. Roteli-Martins CM, Naud PS, De Borba P, et al. Sustained immunogenicity and efficacy of the HPV-16/18 AS04-adjuvanted vaccine: up to 8.4 years of follow-up. Hum Vaccin Immunother. 2012;8(3):390-397.

42. Naud PS, Roteli-Martins CM, De Carvalho NS, et al. Sustained efficacy, immunogenicity, and safety of the HPV-16/18 AS04-adjuvanted vaccine: final analysis of a long-term follow-up study up to 9.4 years post-vaccination. Hum Vaccin Immunother. 2014;10(8).

43. Schwarz TF, Spaczynski M, Schneider A, et al. Persistence of immune response to HPV-16/18 AS04-adjuvanted cervical cancer vaccine in women aged 15-55 years. Hum Vaccin. 2011;7(9):958-965.

44. Schwarz TF, Spaczynski M, Wysocki J, et al. Persistence of immune response 7 years after administration of the HPV-16/18 as04-adjuvanted vaccine to women aged 15-55 years. Poster presented at: Eurogin 2013: HPV at a Crossroads - 30 Years of Research and Practice; November 3-6, 2013; Florence, Italy.

45. Petäjä T, Keränen H, Karppa T, et al. Immunogenicity and safety of human papillomavirus (HPV)-16/18 AS04-adjuvanted vaccine in healthy boys aged 10-18 years. J Adolesc Health. 2009;44(1): 33-40

46. Pedersen C, Petaja T, Strauss G, et al. Immunization of early adolescent females with human papillomavirus type 16 and 18 L1 viruslike particle vaccine containing AS04 adjuvant. J Adolesc Health. 2007;40(6):564-571.

47. Lu B, Kumar A, Castellsagué X, Giuliano AR. Efficacy and safety of prophylactic vaccines against cervical HPV infection and diseases among women: a systematic review and meta-analysis. BMC Infect Dis. 2011;11:13.
48. Kang S, Kim KH, Kim YT, et al. Safety and immunogenicity of a vaccine targeting human papillomavirus types 6, 11, 16 and 18: a randomized, placebo-controlled trial in 176 Korean subjects. Int J Gynecol Cancer. 2008;18:1013-1019.

49. Gonçalves AK, Cobucci RN, Rodrigues HM, de Melo AG, Giraldo PC. Safety, tolerability and side effects of human papillomavirus vaccines: a systematic quantitative review. Braz J Infect Dis. Epub April 27, 2014.

50. Wacholder S, Chen BE, Wilcox A, et al. Risk of miscarriage with bivalent vaccine against human papillomavirus (HPV) types 16 and 18: pooled analysis of two randomised controlled trials. BMJ. 2010;340:c712.

51. Bergman SJ, Collins-Lucey E. Update on human papillomavirus vaccines: life saver or controversy magnet? Clin Microbiol Newsl. 2012;34(11):85-91.

52. Junior GM. Human papillomavirus vaccine: use in pregnancy and malformation risk. Rev Bras Patol Trato Genit Infer. 2012;2:81-82.

53. Garland SM, Ault KA, Gall SA, et al. Pregnancy and infant outcomes in the clinical trials of a human papillomavirus type 6/11/16/18 vaccine: a combined analysis of five randomized controlled trials. Obstet Gynecol. 2009;114(6):1179-1188.

54. Dana A, Buchanan KM, Goss MA, et al. Pregnancy outcomes from the pregnancy registry of a human papillomavirus type 6/11/16/18 vaccine. Obstet Gynecol. 2009;114(6):1170-1178.

55. Slade BA, Leidel L, Vellozzi C, et al. Postlicensure safety surveillance for quadrivalent human papillomavirus recombinant vaccine. JAMA. 2009;302(7):750-757.

56. Franceschini SA. Human papillomavirus vaccine use in men. Rev Bras Patol Trato Genit Infer. 2012;2:92-96.

57. Centers for Disease Control and Prevention (CDC). Human papillomavirus vaccination coverage among adolescent girls, 2007-2012, and postlicensure vaccine safety monitoring, 2006-2013 - United States. MMWR Morb Mortal Wkly Rep. 2013;62(29):591-595.

58. Angelo MG, David MP, Zima J, et al. Pooled analysis of large and long-term safety data from the human papillomavirus-16/18-AS04adjuvanted vaccine clinical trial programme. Pharmacoepidemiol Drug Saf. 2014;23(5):466-479.

59. Descamps D, Hardt K, Spiessens B, et al. Safety of human papillomavirus (HPV)-16/18 AS04-adjuvanted vaccine for cervical cancer prevention. Hum Vaccin. 2009;5(5)332-340.

60. Gee J, Naleway A, Shui I, et al. Monitoring the safety of quadrivalent human papillomavirus vaccine: findings from the Vaccine Safety Datalink. Vaccine. 2011;29(46):8279-8284.

61. Chao C, Klein NP, Velicer CM, et al. Surveillance of autoimmune conditions following routine use of quadrivalent human papillomavirus vaccine. J Intern Med. 2012;271(2):193-203.

62. Klein NP, Hansen J, Chao C, et al. Safety of quadrivalent human papillomavirus vaccine administered routinely to females. Arch Pediatr Adolesc Med. 2012;166(12):1140-1148.

63. Arnheim-Dahlström L, Pasternak B, Svanström H, Sparén P, Hviid A. Autoimmune, neurological, and venous thromboembolic adverse events after immunisation of adolescent girls with quadrivalent human papillomavirus vaccine in Denmark and Sweden: cohort study. BMJ. 2013;347:f5906.

64. Grimaldi-Bensouda L, Guillemot D, Godeau B, et al. Autoimmune disorders and quadrivalent human papillomavirus vaccination of young female subjects. J Intern Med. 2014;275(4):398-408.

65. World Health Organization. Global Advisory Committee on Vaccine Safety, 11-12 December 2013: Human papillomavirus vaccines safety (HPV). Wkly Epidemiol Rec. 2014;89(7):58-60.

66. European Medicines Agency. PRAC recommendations on signals: Adopted at the PRAC meeting of 7-10 April 2014. Available from: http://www.ema.europa.eu/docs/en_GB/document_library/ Other/2014/04/WC500165809.pdf. Accessed September 29, 2014.

67. World Health Organization. Global Advisory Committee on Vaccine Safety, 12-13 June 2013: Update on human papillomavirus vaccines. Wkly Epidemiol Rec. 2013;88(29):309-312. 
68. Denny L. Safety of HPV vaccination: a FIGO statement. Int J Gynaecol Obstet. 2013;123(3):187-188.

69. Joura EA, Kjaer SK, Wheeler CM, et al. HPV antibody levels and clinical efficacy following administration of a prophylactic quadrivalent HPV vaccine. Vaccine. 2008;26(52):6844-6851.

70. European Medicines Agency. CHMP variation assessment report: Gardasil. 2014. http://www.ema.europa.eu/docs/en_GB/document_ library/EPAR_-_Assessment_Report_-_Variation/human/000703/ WC500170695.pdf. Accessed April 25, 2014.

71. Joura E. Efficacy and immunogenicity of a novel 9-valent HPV 11 viruslike particle vaccine in 16- to 26-year-old women. Poster presented at: Eurogin 2013: HPV at a Crossroads - 30 Years of Research and Practice; November 3-6, 2013; Florence, Italy.
72. Viscidi RP, Snyder B, Cu-Uvin S, et al. Human papillomavirus capsid antibody response to natural infection and risk of subsequent HPV infection in HIV-positive and HIV-negative women. Cancer Epidemiol Biomarkers Prev. 2005;14(1):283-288.

73. Eklund C, Unger ER, Nardelli-Haefliger D, Zhou T, Dillner J. International collaborative proficiency study of human papillomavirus type 16 serology. Vaccine. 2012;30(2):294-299.

74. Ferguson M, Wilkinson DE, Zhou T. WHO meeting on the standardization of HPV assays and the role of the WHO HPV Laboratory Network in supporting vaccine introduction held on 24-25 January 2008, Geneva, Switzerland. Vaccine. 2009;27(3):337-347.

\section{Publish your work in this journal}

The International Journal of Women's Health is an international, peerreviewed open-access journal publishing original research, reports, editorials, reviews and commentaries on all aspects of women's healthcare including gynecology, obstetrics, and breast cancer. The manuscript management system is completely online and includes a very quick and fair peer-review system, which is all easy to use. Visit http://www.dovepress.com/testimonials.php to read real quotes from published authors.

Submit your manuscript here: http://www.dovepress.com/international-journal-of-womens-health-journal 